\title{
Perancangan Alas Setrika Sebagai Pengisi Baterai (Battery Charger) dengan Memanfaatkan Energi Panas Terbuang pada Saat Jeda Menyetrika
}

\author{
Tri Wahyu Yulianingrum¹, F Dalu Setiaji², Lukas B Setyawan ${ }^{3}$ \\ Program Studi Teknik Elektro, \\ Fakultas Teknik Elektronika dan Komputer, \\ Universitas Kristen Satya Wacana, Salatiga \\ 1yulianingrum045@gmail.com, 2fdsetiaji@gmail.com, ${ }^{3}$ lukas.b.setyawan@staff.uksw.edu
}

\begin{abstract}
Ringkasan
Pada makalah ini dirancang suatu alas setrika yang akan mengubah energi panas setrika yang terbuang saat jeda menyetrika, menjadi energi listrik menggunakan modul TEG (Thermoelectric Generator) yang selanjutnya akan digunakan untuk mengisi sebuah baterai.
\end{abstract}

Kata kunci: panas, TEG, setrika, charger

\section{Pendahuluan}

Menyetrika pakaian merupakan aktivitas yang dilakukan hampir semua keluarga. Ketika sedang digunakan, setrika tidak secara terus menerus digosokkan pada kain. Ada waktunya pengguna melakukan jeda karena melakukan kegiatan seperti menyiapkan pakaian, melipat pakaian yang telah disetrika, memasang pakaian pada hanger atau pun memasang kancing pada pakaian ataupun bisa juga karena pengguna beristirahat sejenak. Pada saat terjadi jeda tersebut, setrika biasanya hanya diletakkan pada posisi berdiri atau diletakkan pada suatu alas setrika konvensional (Gambar 1) sehingga energi panasnya terbuang sia-sia. Pada makalah ini panas setrika yang terbuang ini akan diubah menjadi energi listrik dengan menggunakan modul thermoelectric generator (TEG).

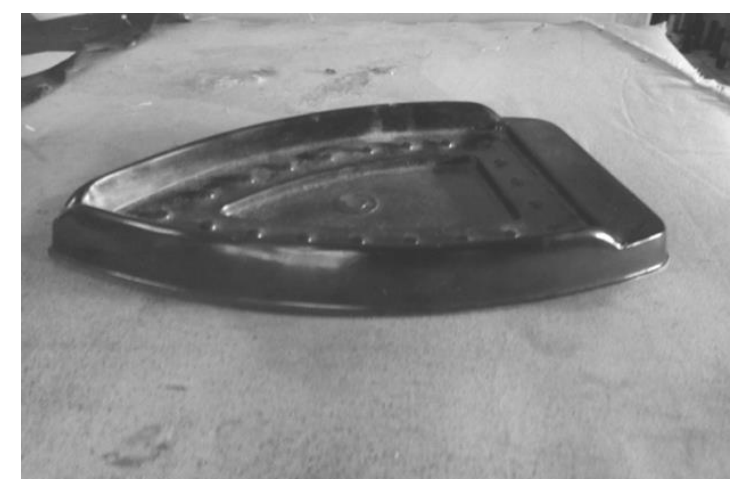

Gambar 1. Alas setrika konvensional 
Ide dasar dari makalah ini adalah mengubah energi panas terbuang tersebut menjadi energi listrik menggunakan TEG, lalu menyimpannya ke dalam sebuah baterai isi ulang. Pada saat jeda menyetrika, setrika akan ditempatkan pada modul alas setrika yang akan dibuat, di mana TEG akan ditempatkan sehingga sisi panasnya bersentuhan dengan sisi bawah setrika.

Memang pada saat setrika ditempelkan pada alas setrika, akan terdapat penurunan suhu sisi bawah setrika. Namun penurunan suhu tersebut tidak akan signifikan mempengaruhi kinerja setrika ketika akan digunakan kembali untuk menghaluskan kerut pada pakaian. Karena alas setrika yang dibuat pada dasarnya adalah sama dengan alas setrika konvensional dalam hal menyerap energi panas setrika.

Lagipula penurunan suhu setrika sebesar beberapa derajat celcius tidak akan menjadi masalah. Hal ini karena kendali suhu pada setrika listrik yang telah ada, yaitu dengan menggunakan bimetal, mentoleransi ralat cukup besar yang ditunjukkan dengan nilai histerisis yang dapat mencapai $30^{\circ} \mathrm{C}$ [1]. Jika diinginkan kendali suhu setrika dengan lebih tepat maka harus dilakukan perbaikan dalam metode pengendalian suhunya[1],[2].

Untuk menguatkan hipotesis bahwa penggunaan alas setrika tidak akan mengurangi kinerja setrika, dilakukan eksperimen awal dengan menyetrika pakaian dengan dua kondisi, yaitu Gambar 2 ketika jeda setrika diposisikan berdiri (tanpa alas, suhu terukur $170^{\circ} \mathrm{C}$ ) dan Gambar 3 ketika jeda setrika diletakkan pada alas konvensional (suhu terukur $168^{\circ} \mathrm{C}$ ). Hasilnya menunjukkan bahwa pakaian akan sama halusnya dengan waktu menyetrika yang relatif sama.

a
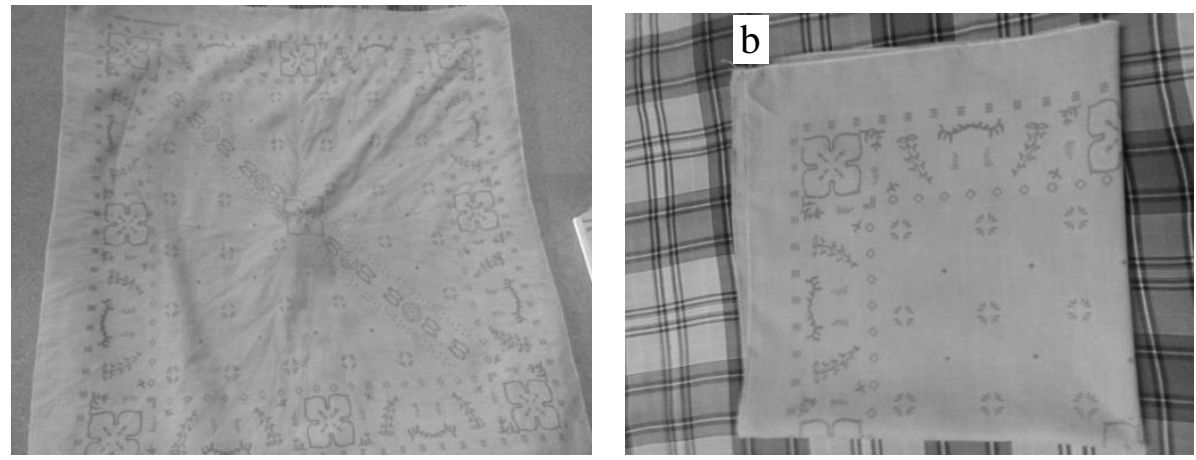

Gambar 2. Pakaian yang disetrika dengan setrika tidak ditempelkan pada alas setrika, a) sebelum disetrika, b) sesudah disetrika

a
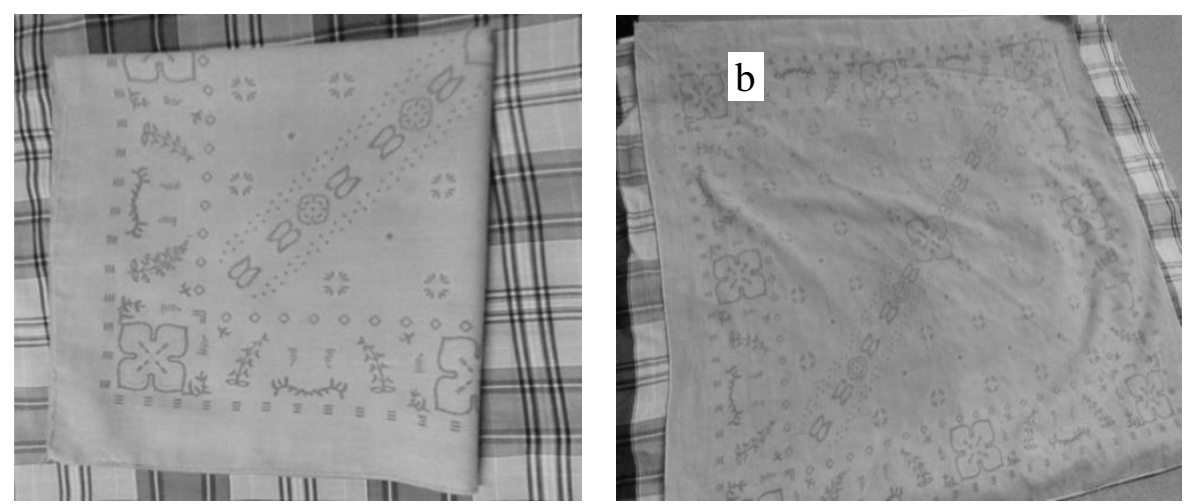

Gambar 3. Pakaian yang disetrika dengan setrika yang sebelumnya ditempelkan pada alas setrika konvensional, a) sebelum disetrika, b) sesudah disetrika 


\section{Perancangan}

Alat yang dibuat berbentuk alas setrika yang bersifat portable sehingga mudah dipindah tempatkan. Sumber panas yang digunakan berasal dari panas setrika listrik yang terbuang. Bagian alas setrika yang akan bersentuhan dengan bagian bawah setrika, terbuat dari alumunium sebagai kolektor panas. Bagian ini akan bersentuhan dengan sisi panas dari empat buah TEG yang berfungsi mengubah energi panas menjadi energi listrik. Sedangkan pada bagian sisi dingin TEG dipasang pendingin (heat sink) yang dicelupkan ke dalam diberi oli agar gradien suhu antara kedua sisi TEG tetap tinggi. Tegangan keluaran TEG akan menjadi masukan bagi rangkaian konverter DC ke DC menggunakan LM2577-Adj yang akan menghasilkan tegangan stabil, sebagai pengisi (charger) sebuah baterai kering lythium polymer 3,7V,380mAh yang akan berfungsi sebagai penyimpan energi yang dihasilkan. Diagram kotak keseluruhan alat ditunjukkan pada Gambar 1.

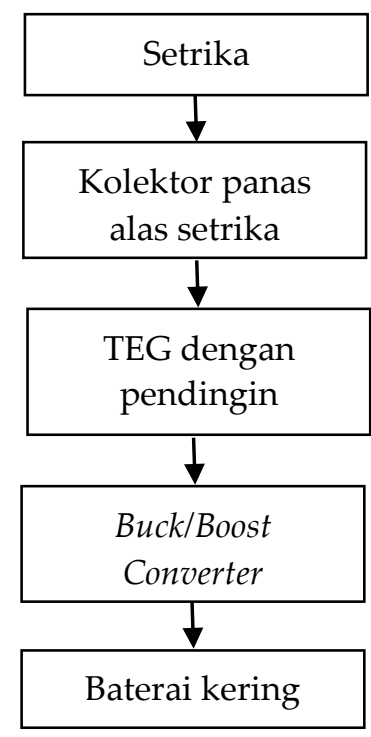

Gambar 4. Diagram kotak keseluruhan alat yang dibuat

Sedangkan desain fisik alas setrika yang dibuat ditunjukkan pada Gambar 5.

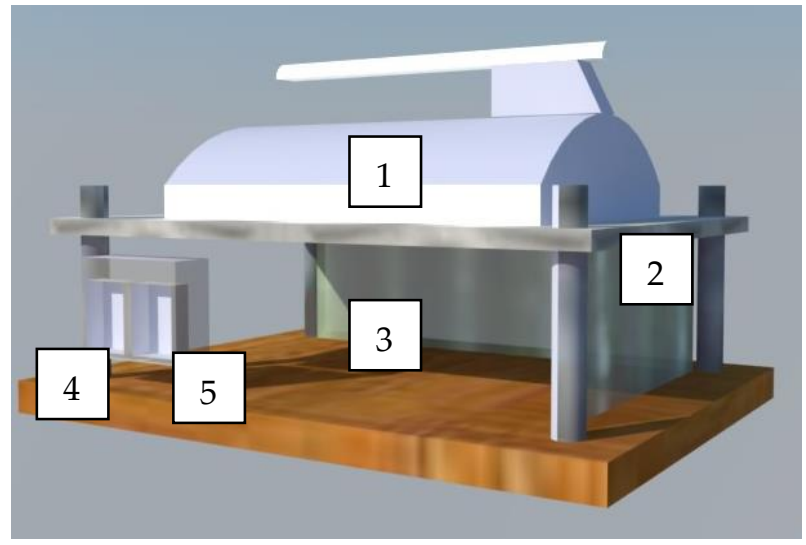

Keterangan gambar:

1. Setrika

2. Kolektor panas

3. TEG dengan Pendingin

4. Buck-Boost Converter

5. Baterai Kering

Gambar 5. Wujud fisik alas setrika yang dibuat 
Berikut ini akan dijelaskan bagian-bagian alas setrika yang dibuat.

\subsection{Kolektor Panas Alas Setrika}

Bagian ini merupakan bagian alas setrika yang akan bersentuhan dengan bagian bawah setrika saat setrika tersebut masih sedang jeda tidak digunakan. Kolektor panas yang dibuat dari alumunium setebal $3 \mathrm{~mm}$ dan berukuran $25 \mathrm{~cm} \times 15 \mathrm{~cm}$ ini juga merupakan penyalur panas dari setrika menuju sisi panas TEG. Alumunium dipililih karena ringan, kuat, memiliki konduktivitas panas yang baik serta mudah diperoleh dipasaran.

Bagian sisi dingin TEG ditempelkan pada alumunium (heat sink) sebagai penyerap. Heat sink ini dicelupkan dalam cairan oli dengan volume sekitar 1,8 liter yang dikemas dalam wadah kaca yang kedap yang berukuran $21 \mathrm{~cm} \times 11 \mathrm{~cm} \times 8 \mathrm{~cm}$. Oli dipilih sebagai pendingin karena titik didihnya yang tinggi, mencapai $300^{\circ} \mathrm{C}$.

\subsection{Thermoelectric Generator (TEG)}

$T E G$ akan menghasilkan tegangan ketika terdapat gradien temperatur atau $\Delta T$ antara sisi panas dan sisi dingin. Modul TEG yang terbuat dari bahan $B i-T e$ ini akan bekerja hingga suhu $330^{\circ} \mathrm{C}$. Empat buah TEG tipe TE-MOD-5W5V-30S yang digunakan disusun secara seri. Tujuan pemasangan secara seri ini adalah untuk menjumlahkan tegangan keluaran masing-masing TEG. Masing-masing TEG tersebut berukuran $3 \mathrm{~cm} \times 3 \mathrm{~cm} \times 5 \mathrm{~mm}$ (Gambar 6).

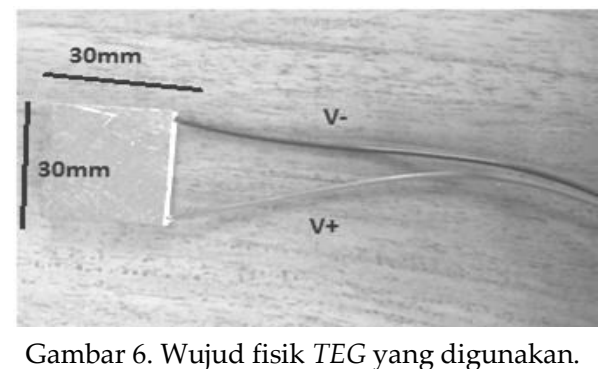

Kedua sisi TEG diolesi dengan pasta termal agar panas merambat dengan baik. Hal ini perlu dilakukan karena dalam antarmuka apapun selalu terdapat rongga mikroskopis yang dapat menjebak udara masuk di antaranya sehingga mengakibatkan kerugian perambatan panas. Dengan penggunaan pasta termal akan mengisi rongga mikroskopis sehingga meningkatkan konduktivitas termal.

\subsection{Buck-Boost Converter dan Baterai Kering}

Tegangan keluaran TEG bervariasi tergantung pada suhu antar kedua sisinya $(\Delta T)$ dan beban yang dipasang pada keluarannya. Berdasarkan hasil pengujian, keempat TEG menghasilkan tegangan antara 3,9V sampai 7,9V ketika dibebani resistor senilai $30 \Omega$. Nilai $30 \Omega$ tersebut adalah hambatan dalam dari susunan keempat TEG seri tersebut. Untuk dapat mengisi baterai kering tipe lythium polymer 3,7V 380mAh maka keluaran TEG akan distabilkan pada nilai 4,7V. Untuk itu digunakan rangkaian DC-DC Buck-Boost Converter berbasis IC LM-2577-Adj yang bisa menaikkan dan menurunkan tegangan DC masukannya (yaitu keluaran $T E G$ ) untuk menghasilkan tegangan keluaran yang konstan. Rangkaian yang digunakan ditunjukkan pada Gambar 7. Pemilihan nilai komponen rangkaian tersebut mengacu pada [3]. Pada keluaran rangkaian juga dipasang LED indikator yang menyala jika baterai terisi (jika tegangan TEG bernilai di atas 1,23V 
sehingga keluaran rangkaian Buck- Boost Converter bernilai 4,7V). Keluaran rangkaian ini langsung dihubungkan ke baterai kering sebagai penyimpan energi.

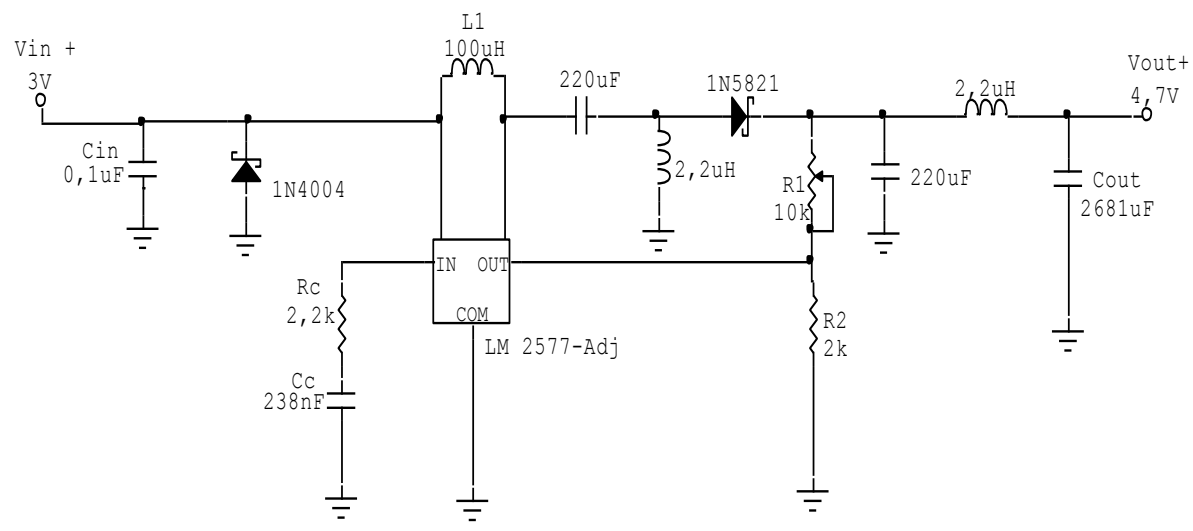

Gambar 7. Rangkaian Buck-Boost yang digunakan.

Wujud alas setrika yang telah dibuat ditunjukkan pada Gambar 8 dengan dimensi $25 \mathrm{~cm}(\mathrm{P}) \times 15 \mathrm{~cm}(\mathrm{~L}) \times 10 \mathrm{~cm}(\mathrm{~T})$ dan berat $3,5 \mathrm{~kg}$. Ketika digunakan, setrika cukup diletakkan di atasnya seperti halnya menggunakan alas setrika konvensional. Terminal yang ditunjukkan pada gambar tersebut dapat digunakan untuk mengukur arus dan tegangan baterai saat pengisian berlangsung.

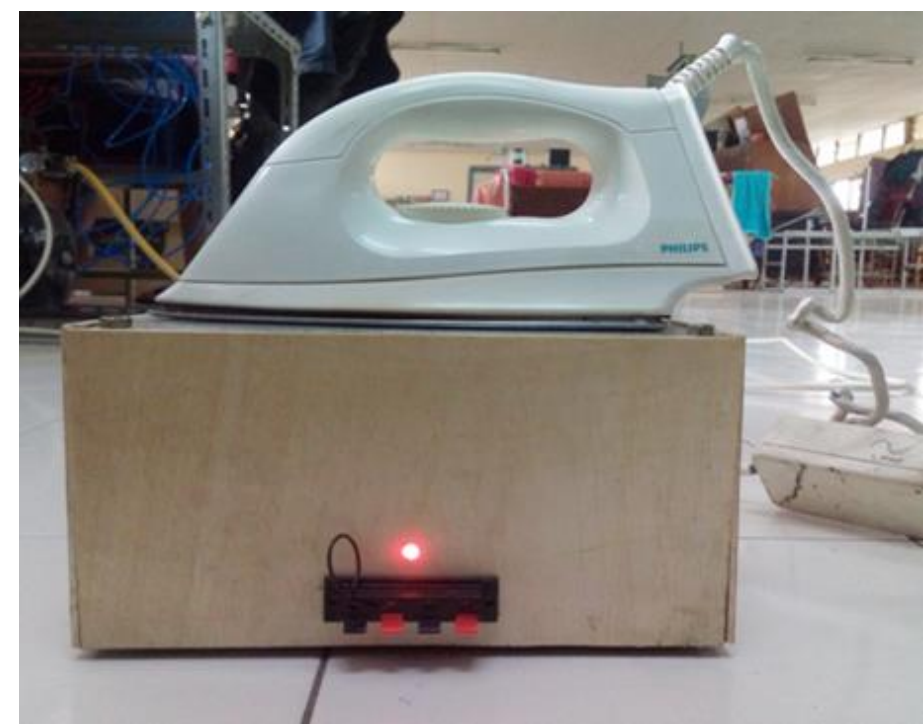

Gambar 8. Alas setrika yang telah dirancang dan penempatan setrika di atasnya

\section{Pengujian dan Analisis}

Pengujian pertama yang dilakukan adalah menguji dua cairan pendingin yaitu air (sebagai pembanding) dan oli yang akan digunakan. Hasil pengujian menunjukkan bahwa air dengan volume yang lebih banyak yaitu 3,3 liter dibandingkan dengan oli bervolume 1,84 liter yang keduanya sama-sama dipanaskan dengan setrika selama lima menit mengalami kenaikan suhu yang jauh berbeda. Suhu air naik $9,5^{\circ} \mathrm{C}$ sedangkan suhu oli hanya naik $2,5^{\circ} \mathrm{C}$. Dengan demikian oli akan digunakan sebagai pendingin pada alat ini. 
Kemudian diuji besarnya tegangan keluaran TEG dengan memasang beban yang bervariasi pada keluarannya. Pada pengujian ini digunakan setrika berdaya maksimal $350 \mathrm{~W}$ yang diletakkan di atas alas setrika yang dibuat. Didapatkan bahwa keluaran dari sususan seri empat buah TEG akan memberikan daya maksimum jika nilai beban $30 \Omega$ yang menghasilkan daya sebesar 2,23 W.

Selanjutnya dilakukan pengujian pengaruh $\Delta T$ terhadap nilai keluaran TEG (VоuT) dengan hasil ditunjukkan Gambar 9. Pada pengujian ini diberikan beban $30 \Omega$ dan suhu diukur menggunakan thermogan Fluke tipe 68-IR Thermometer.

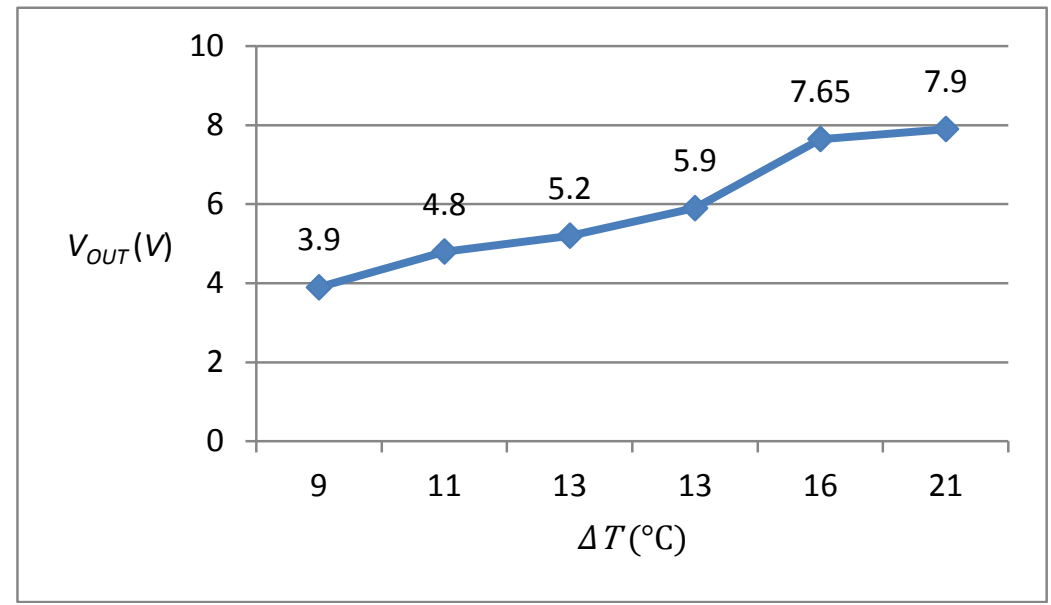

Gambar 9. Grafik perubahan Vout terhadap $\Delta \mathrm{T}$.

Hasil pengujian tersebut menunjukkan bahwa tegangan keluaran TEG (Vоит) bertambah besar dengan bertambahnya gradien temperatur $(\Delta T)$ antara kedua sisinya, walaupun kenaikannya tidak benar-benar linear.

Selanjutnya dilakukan pengujian rangkaian Buck-Boost Converter dengan memberi masukan berupa tegangan DC yang berasal dari catu daya laboratorium merk GW tipe GPS-3030D. Hasil pengujian menunjukkan bahwa dengan tegangan minimal sebesar $2,86 \mathrm{~V}$ rangkaian sudah mampu memberikan tegangan keluaran sebesar $4,73 \mathrm{~V}$ atau modul bekerja sebagai boost converter. Sedangkan saat tegangan masukannya berada di atas $4,7 \mathrm{~V}$ maka keluaran tetap bernilai sekitar $4,7 \mathrm{~V}$ yang berarti rangkaian dapat bekerja sebagai buck converter. Dengan demikian jangkauan tegangan keluaran TEG (Gambar 9) dapat digunakan untuk memberi masukan rangkaian Buck-Boost Converter agar menghasilkan tegangan keluaran stabil di sekitar 4,7V.

Tegangan keluaran rangkaian rangkaian Buck-Boost Converter tersebut selanjutnya digunakan untuk mengisi baterai. Pengukuran arus dan tegangan baterai yang sedang diisi, dilakukan dengan dial pengatur pengatur panas setrika diposisikan pada kondisi minimum dan juga maksimum (paling panas).

Ketika dial diposisikan minimum, hasilnya ditunjukkan pada Gambar 10 dan 11. Berdasarkan grafik tersebut, menggunakan rumus energi, $E=V$.I.t, dapat dihitung energi yang diisikan pada baterai selama pengujian (4 menit) yaitu $0,014 \mathrm{Wh}$. Karena baterai yang digunakan adalah 3,7V, 380mAh (kapasitas maksimalnya 1,41Wh), maka selama 4 menit tersebut (dengan panas setrika minimal), baterai telah terisi sebanyak $1 \%$ saja. 
Perancangan Alas Setrika Sebagai Pengisi Baterai (Battery Charger) dengan Memanfaatkan Energi Panas Terbuang pada Saat Jeda Menyetrika Tri Wahyu Yulianingrum, F Dalu Setiaji, Lukas B Setyawan

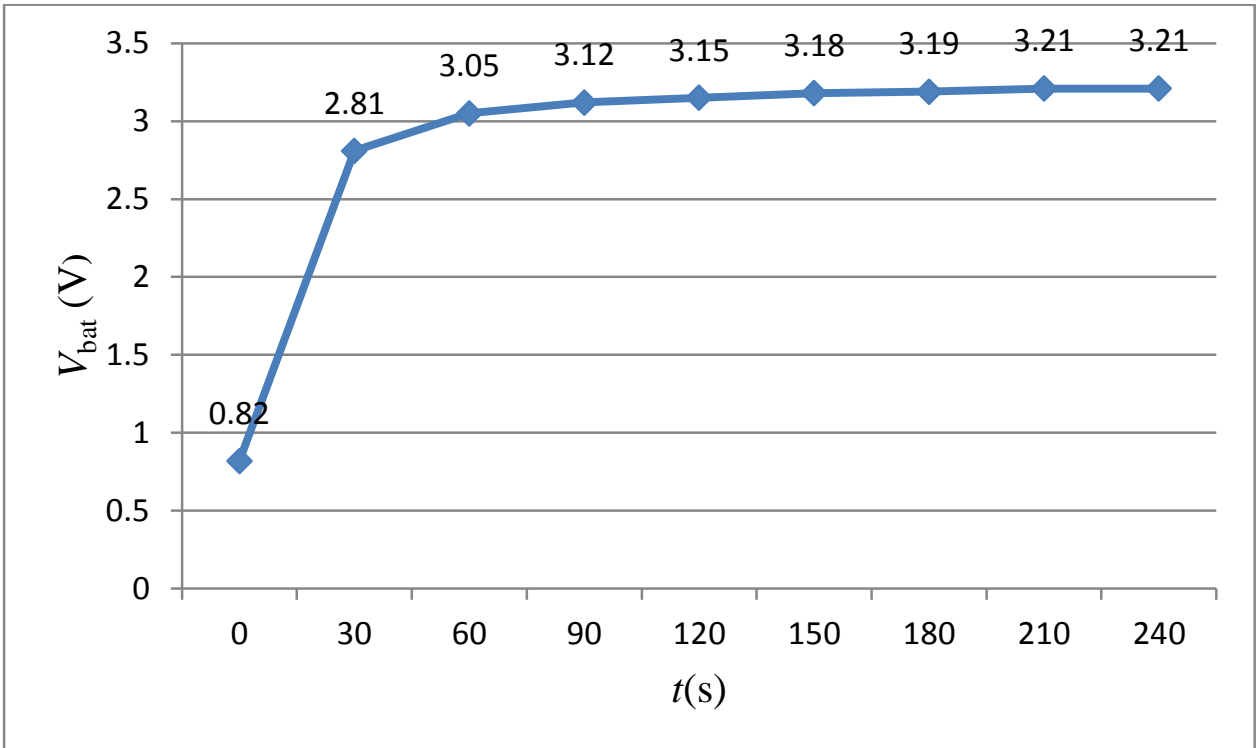

Gambar 10. Grafik tegangan baterai (Vbat) sebagai fungsi waktu selama pengisian, dengan panas setrika diatur minimal.

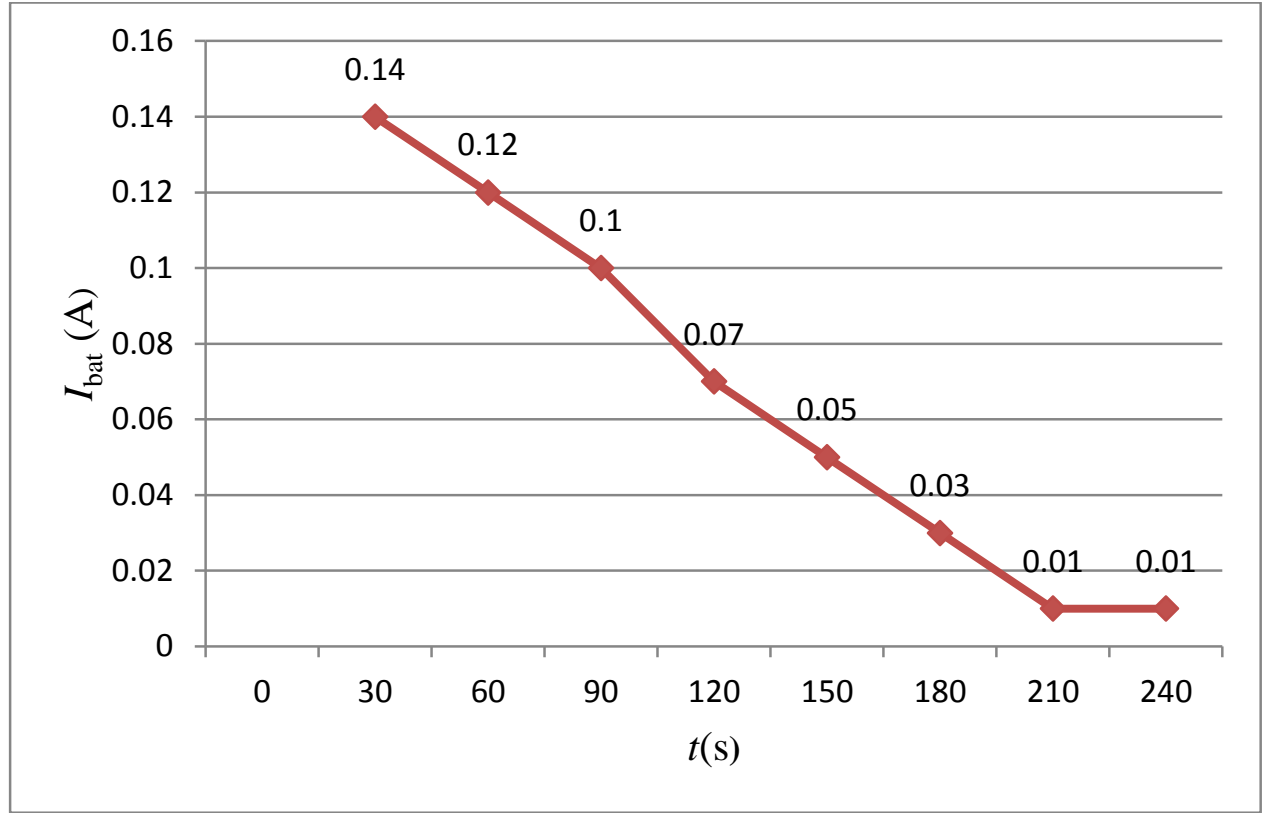

Gambar 11. Grafik arus baterai (lbat) sebagai fungsi waktu selama pengisian, dengan panas setrika diatur minimal.

Selanjutnya ketika dial diposisikan maksimum, hasilnya ditunjukkan pada Gambar 12 dan 13. Berdasarkan grafik tersebut, maka selama 10 menit pengisian baterai (dengan panas setrika maksimal), baterai telah terisi sebanyak $8,51 \%$. 


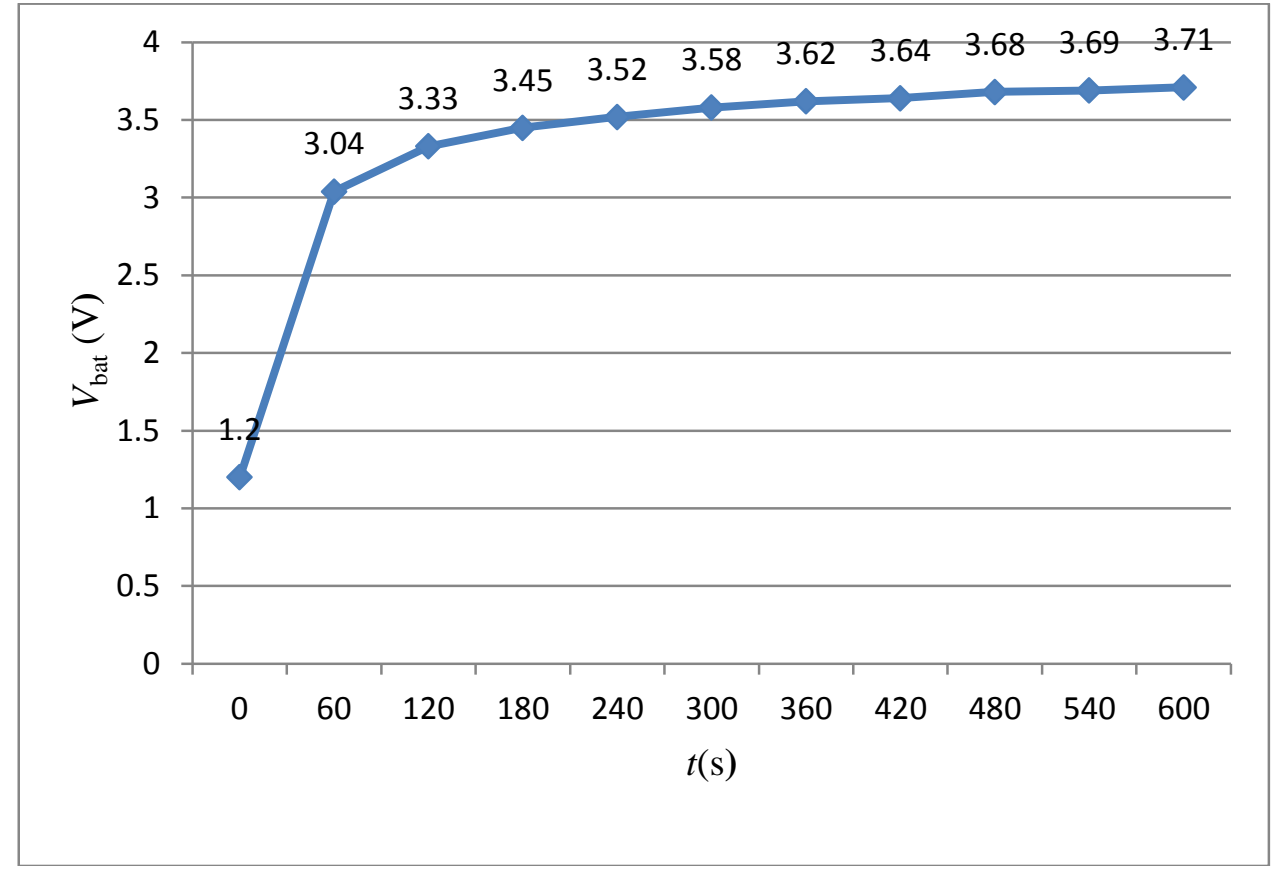

Gambar 12. Grafik tegangan baterai (Vbat) sebagai fungsi waktu selama pengisian, dengan panas setrika diatur maksimal.

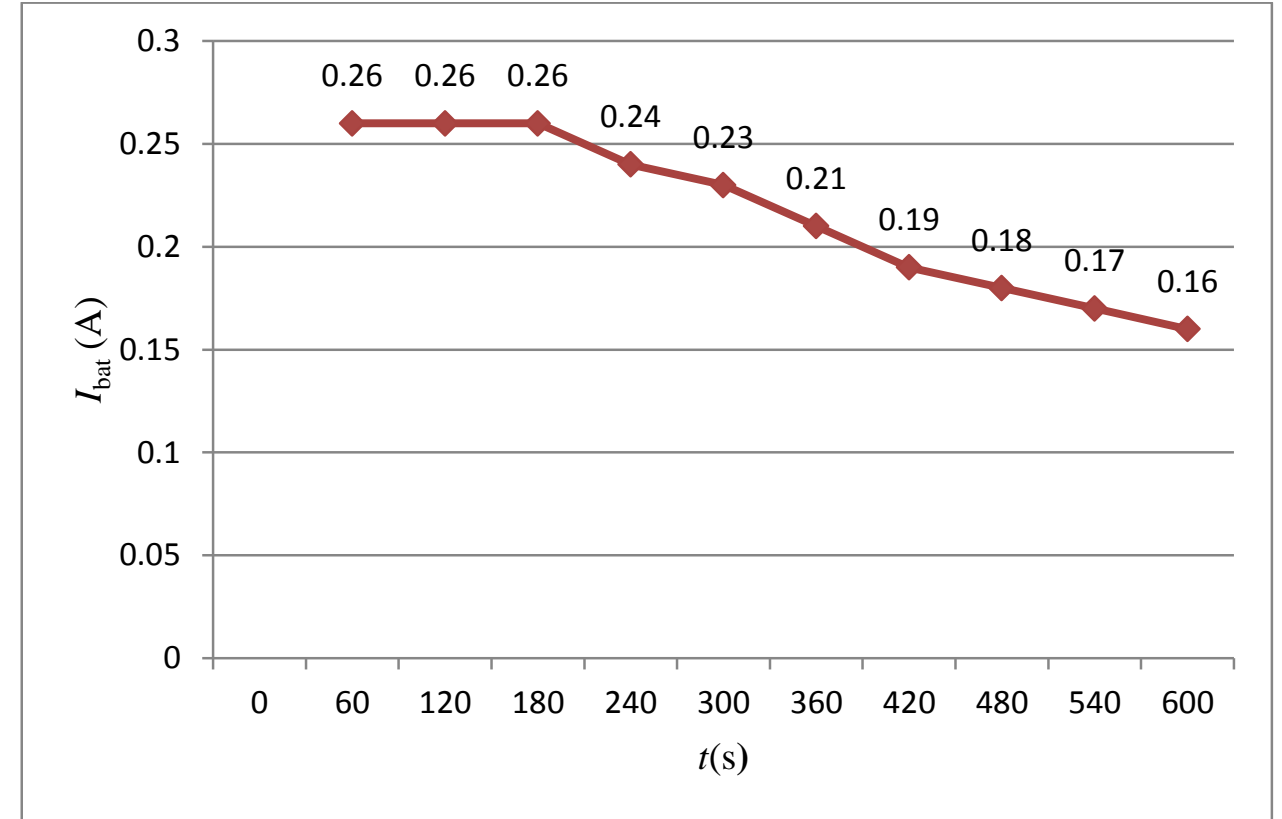

Gambar 13. Grafik arus baterai (Ibat) sebagai fungsi waktu selama pengisian, dengan panas setrika diatur maksimal.

Pengujian juga dilakukan untuk mengambil energi panas dari setrika yang telah selesai digunakan. Caranya dengan memanaskan setrika lalu memutus catu daya PLN yang digunakan dan menempatkan setrika tersebut pada alas setrika yang telah dibuat. Hasil pengukurannya ditunjukkan pada Gambar 14 dan 15. 
Perancangan Alas Setrika Sebagai Pengisi Baterai (Battery Charger) dengan Memanfaatkan Energi Panas Terbuang pada Saat Jeda Menyetrika Tri Wahyu Yulianingrum, F Dalu Setiaji, Lukas B Setyawan

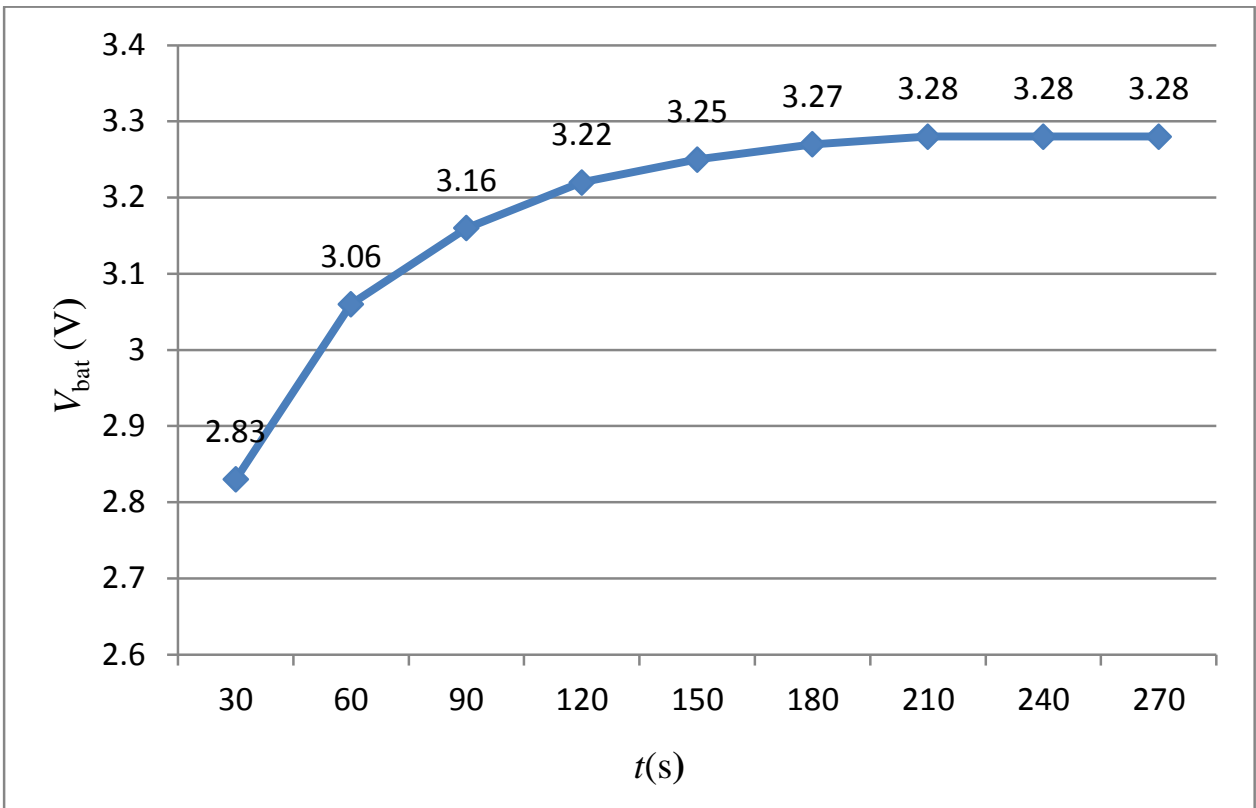

Gambar 14. Grafik tegangan baterai ( $V_{\text {bat}}$ ) sebagai fungsi waktu selama pengisian, dengan sisa panas setrika yang masih panas (catu daya setrika diputus)

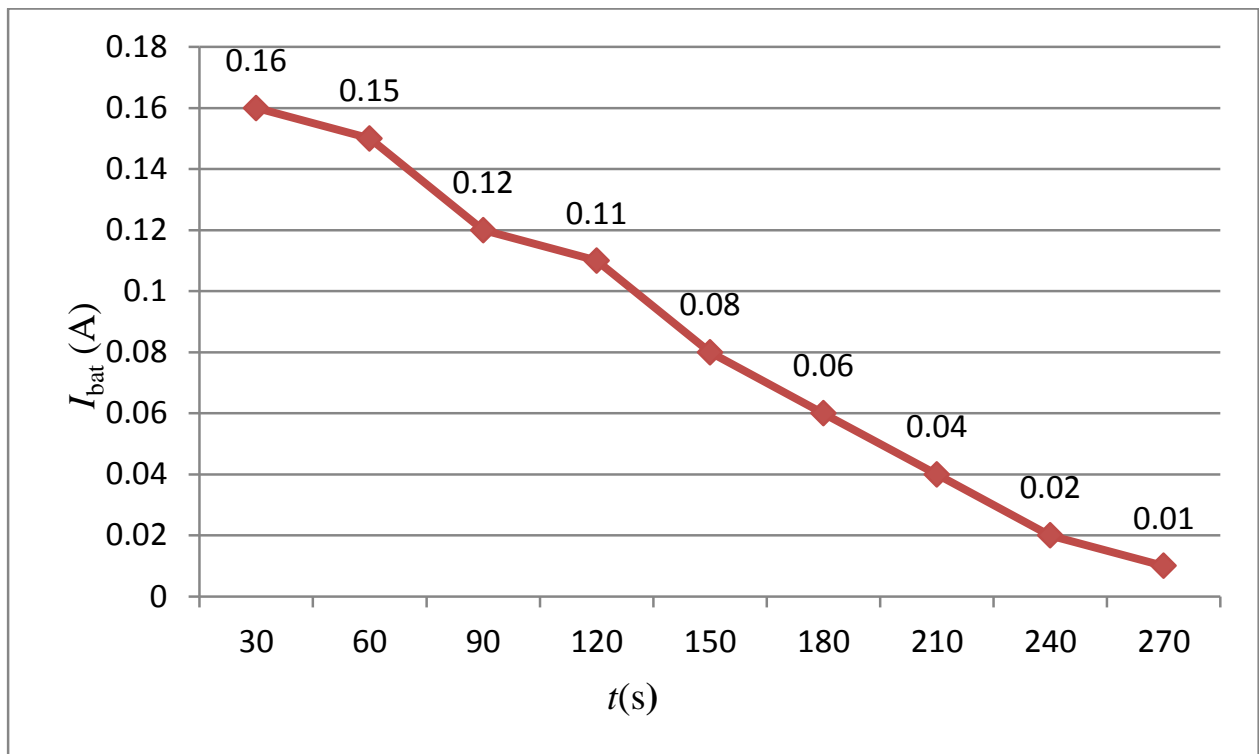

Gambar 15. Grafik arus baterai (Ibat) sebagai fungsi waktu selama pengisian, dengan sisa panas setrika yang masih panas (catu daya setrika diputus)

Dengan memanfaatkan energi sisa panas setrika yang telah dipanaskan tersebut, dalam waktu 270s (4,5menit) didapatkan bahwa baterai dapat tersisa sebanyak 1,41\% atau $0,02 \mathrm{Wh}$. Energi yang relatif kecil ini masih bisa bermanfaat secara praktis. Berdasarkan hasil pengujian, energi ini cukup untuk menyalakan sebuah lampu senter darurat dengan LED tunggal selama sekitar satu jam (Gambar 16). 


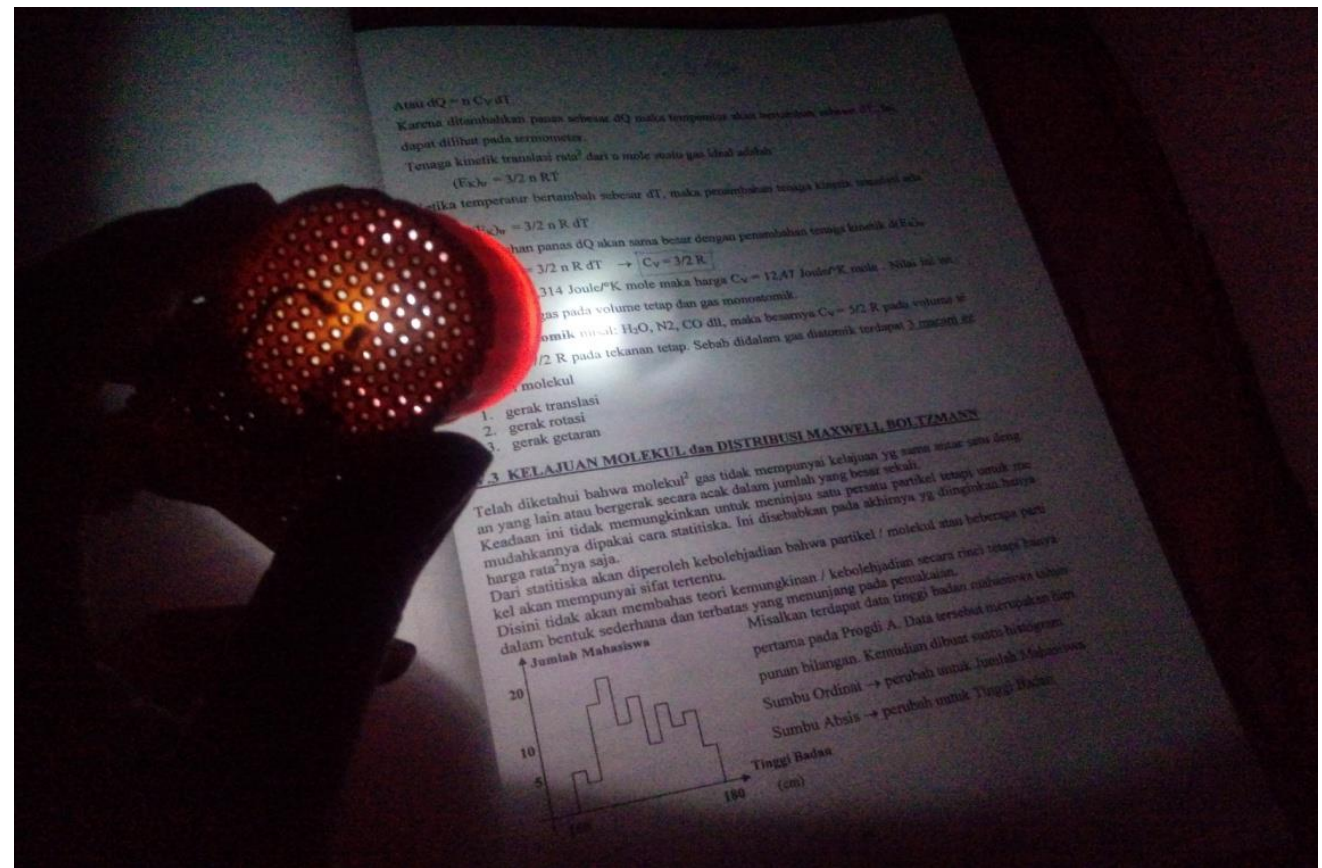

Gambar 16. Energi dari sisa panas setrika (catu daya setrika diputus) yang telah tersimpan di baterai dapat menyalakan lampu LED tunggal selama sekitar 1 jam.

Pengujian terakhir dilakukan dengan menggunakan setrika untuk menyetrika pakaian secara wajar, selama satu jam. Selama jeda menyetrika, setrika diletakkan pada alas setrika yang dibuat. Hasil pengujian menunjukkan bahwa energi yang dapat diambil selama proses tersebut dan disimpan di baterai adalah sebesar 1,11Wh atau sekitar $8 \%$ dari kapasitas baterai yang digunakan.

\section{Kesimpulan}

Alas setrika portabel yang dibuat, telah mampu memanfaatkan energi panas yang terbuang saat jeda menyetrika menjadi energi listrik yang disimpan dalam baterai. Selama proses menyetrika pakaian satu jam, energi yang tersimpan ke dalam baterai adalah sebesar $0,11 \mathrm{Wh}$ dari kapasitas total baterai 1,41Wh atau sebesar $8 \%$. Energi yang tersimpan tersebut secara praktis dapat dimanfaatkan misalnya untuk penerangan darurat selama sumber listrik PLN padam pada malam hari.

\section{Daftar Pustaka}

[1] P. Telcer, Cloth Iron Controlled by MC9RS08KA2, Freescale Czech System Application Laboratory, 2008.

[2] E.H. Kamaleshwar, S. Karishma, Fully Automated Iron Box, Indian Journal of Science, 2015.

[3] National Semiconductor, LM2577-ADJ Datasheet, www.alldatasheet.com, diakses pada 10 Desember 2014 